\title{
RANCANGAN APLIKASI PENJUALAN PERLENGKAPAN DAN MAINAN ANAK MENGGUNAKAN KONSEP MODEL VIEW CONTROLLER (MVC)
}

\author{
Syaiful Anwar \\ Program Studi Sistem Informasi, Universitas Bina Sarana Informatika, Jakarta, Indonesia \\ Jl. Kamal Raya No.18 Ring Road Barat, Cengkareng Jakarta Barat \\ e-mail: anwarxmedia@gmail.com \\ * Korespondensi: e-mail: anwarxmedia@gmail.com
}

\begin{abstract}
ABSTRAK
Perkembangan teknologi informasi semakin dikalangan dunia usaha dan banyak perusahaan dibidang retail mulai menggembangkan sistem administrasinya dengan menggunakan teknologi informasi. Tak dipungkiri penggunaan teknologi saat ini merupakan kebutuhan yang tidak bisa ditolak dalam mengembankan dan meningkatkan keuntungan usaha suatu perusahaan. Salah satunya adalah dengan menggunakan aplikasi yang berbasis web secara online. Dengan menggunakan aplikasi berbasis web dapat menjadi solusi dalam memecahkan permasalan yang terkait dengan pemasaran dan penjualan produk. Sistem informasi penjualan berbasis web mulai dikembangkan oleh PT Harmoni Lintas Gaya, sistem informasi tersebut mengolah data penjualan perlengkapan dan mainan anak. Dalam menyusun dan merancang sistem informasi penjualan ini dapat menggunakan framework Codeigniter dengan metode Model-View-Controller (MVC). Konsep MVC ini melakukan pemisahan bagian berupa Model, View, dan Controller. Dengan konsep ini dapat mempermudah dalam rancang bangun aplikasi penjualan perlengkapan dan mainan anak. Dalam pembagunan sistem informasi ini juga menggunakan basis data dan bahasa pemrograman yang dapat memberikan hasil tampilan yang lebih user friendly dan mudah digunakan oleh pemakai atau user. Hasil yang ingin diharapkan adalah sistem informasi atau aplikasi penjualan perlengkapan dan mainan anak pada PT. Harmoni Lintas Gaya dapat memberikan pemecahan masalah terkait dengan memperluas jangkauan pemasaran dan meningkatkan nilai penjualan serta memudahkan user dalam melakukan transaksi penjualan perlengkapan dan mainan anak. Aplikasi ini mendapatkan nilai kelayakan sebesar $82.8 \%$, artinya aplikasi ini layak diterapkan pada sistem penjualan perusahaan.
\end{abstract}

Kata Kunci: Codeigniter, Penjualan, Sistem Informasi, $M V C$

\begin{abstract}
The development of information technology is increasingly among the business world and many companies in the retail sector have begun to develop their administrative systems using information technology. No doubt the use of technology today is a necessity that cannot be denied in developing and increasing a company's business profits. One way is to use web-based applications online. By using a web-based application can be a solution in solving problems associated with marketing and selling products. A web-based sales information system was developed by PT Harmoni Lintas Gaya, the information system processes sales data for equipment and children's toys. In compiling and designing this sales information system, it can use the Codeigniter framework with the Model-View-Controller (MVC) method. This MVC concept separates parts in the form of Model, View, and Controller. With this concept, it can be easier to design and build applications for the sale of children's equipment and toys. In building this information system also uses a database and programming language that can provide results that are more user friendly and easy to use by the user or user. The desired result is an information system or application sales of equipment and toys for children at PT. Harmoni Lintas Gaya can provide solutions to problems associated with expanding marketing reach and increasing sales value as well as making it easier for users to make sales transactions for equipment and children's toys. This application gets a feasibility value of $82.8 \%$, meaning that this application is feasible to be applied to the company's sales system.
\end{abstract}

Keywords: Codeigniter, Sales, Information Systems, MVC

\section{PENDAHULUAN}

Kemajuan teknologi informasi pada masa kini mendorong manusia untuk terus berinovasi dalam mendapatkan informasi yang lebih cepat dan mudah. Kemajuan ini terlihat semakin pesatnya perkembangan dalam dunia bisnis, terutama dalam dunia perdagangan atau ritel. Saat ini bisnis ritel tidak terlepas dari dunia digital dalam pemanfaatan teknologi internet. Betapa tidak, karena internet secara lengkap menyediakan kebutuhan akan informasi. Berbicara tentang internet, internet tidak lepas dari sebuah website. Website adalah kumpulan dari berbagai macam halaman situs, yang terangkum didalam sebuah domain atau juga subdomain, yang lebih tepatnya berada didalam WWW (World Wide Web) yang tentunya terdapat didalam internet. [1]

Pada era industri 4.0 dimana perkembangan dunia internet sudah menjadi suatu kebutuhan dalam membantu suatu pekerjaan. Peranan teknologi dapat mengurangi tugas manusia dalam menangani aktivitas bisnis. Teknologi informasi yang berbasis internet dapat mengurangi waktu dan memudahkan dalam menemukan produk atau barang 
yang diinginkan. Akhir-akhir ini penggunaan internet sangat mendominasi seluruh kegiatan di atas permukaan bumi dimasa kini dan masa datang dan secara umum akan berubah menjadi alat untuk persaingan antara perusahaan yang satu dengan yang lainnya. Internet (Interconnected Network) adalah sebutan untuk jaringan komputer global yang menghubungkan satu komputer dengan komputer lain yang ada diseluruh dunia.[2]

PT Harmoni Lintas Gaya adalah perusahaan yang bergerak dalam bidang penjualan ritel. Barang yang dijual mencakup perlengkapan bayi dan mainan anak-anak. Untuk perlengkapan bayi seperti gift set for new born, diaper bag, bedding set, baby nest, bedcover, perlak dan lain sebagainya. Sedangkan untuk mainan anak-anak meliputi mainan dengan karakter Disney seperti figure Minni Mouse, Mickey Mouse, Avenger dan lain sebagainya.

Untuk meningkatkan pemasaran dan hasil penjualan maka konsep penjualan harus dikembangkan lagi. Melihat sekarang dunia perdagangan sudah banyak yang beralih ke dunia digital dan berbelanja online sudah menjadi gaya hidup kalangan masyarakat dalam dunia modern ini. Suatu perusahaan memiliki sebuah website adalah suatu hal yang wajib dalam menghadapi persaingan dalam dunia bisnis ini.

Bahasa pemograman ini sangat populer dan telah digunakan oleh beberapa perusahaan raksasa pengembang web. Salah satu metode dalam pembuatan program web menggunakan metode Model View Controller. [3]

Model-View-Controller (MVC) adalah konsep yang digunakan untuk meng-enkapsulasi data bersama dengan pemrosesan (model),mengisolasi dari proses manipulasi (controller) dan tampilan (view) untuk direpresentasikan pada sebuah user interface. Dari hasil analisa,perancangan, pengujian dan implementasi program yang telah dilakukan terhadap aplikasi.[4]Sehingga akan memudahkan dalam penyusunan sebuah aplikasi yang dapat mendukung sistem di perusahaan.

Dalam hal terkait penelitian ini, sebagai prosedur pemecahan masalah yang diselidiki adalah dengan menggambarkan keadaan subjek atau objek yang berupa orang, lembaga, masyarakat dan yang lainnya berdasarkan fakta, karena pencarian informasi berdasarkan data yang akurat dalam merancang sistem yang diperlukan[5]. Atas dasar identifikasi masalah yang telah dipaparkan, maka rumusan masalah pada penelitian ini adalah bagaimana membuat sistem informasi berbasis website untuk meningkatkan penjualan pada PT Harmoni Lintas Gaya.

\subsection{Penelitian Terkait}

\section{TINJAUAN PUSTAKA}

Diana, Febrianti dari Universitas Muhammadiyah Bengkulu (2017), dengan judul "Implementasi Model View Controller (Mvc) Pada Aplikasi Doa Harian Untuk Anak Muslim Berbasis Android". Tujuan penelitian ini adalah membuat desain aplikasi do'a harian untuk anak muslim berbasis android yang menggunakan metode MVC. Model-View-Controller (MVC) adalah konsep yang digunakan untuk meng-enkapsulasi data bersama dengan pemrosesan (model),mengisolasi dari proses manipulasi (controller) dan tampilan (view) untuk direpresentasikan pada sebuah user interface. Dari hasil analisa,perancangan, pengujian dan implementasi program yang telah dilakukan terhadap aplikasi Doa Harian Anak ini disimpulkan Model View Controller dapat diterapkan dalam pengembangan aplikasi dan tentunya program atau aplikasi lebih terstruktur [4].

Suendri dari Universitas Islam Negeri Sumatera Utara (2018), dengan judul "Penerapan Konsep Model View Controller Pada Perancangan Sistem Manajemen Software Berbasis Web". Tujuan dari penelitian ini untuk melakukan pencatatan seluruh produk software yang dikembang oleh perusahaan yang bergerak dibidang perangkat lunak. Semakin banyaknya pelanggan yang menggunakan produk tersebut akan lebih memudahkan jika perusahaan mempunyai sebuah sistem yang bisa diakses secara realtime dan mencatat seluruh data-data penting software. Konsep Model View Contoller (MVC) merupakan sebuah arsitektur dimana proses pada sistem dipisah menjadi tiga bagian dengan tugas-tugasnya. Penelitian ini diharapkan bisa membantu perusahaan perangkat lunak dalam melakukan pencatatan produk yang telah dijual kepada pelanggan[6].

Khana Wijaya, Andi Christian dari STMIK Prabumulih (2019), dengan judul "Implementasi Metode Model View Controller (MVC) Dalam Rancang Bangun Website SMK Yayasan Bakti Prabumulih". Tujuan dari penelitian ini pembangunan website SMK Yayasan Bakti Prabumulih. Situs sekolah memiliki peran yang sangat penting dalam pendidikan. Yayasan SMK Bakti Prabumulih adalah salah satu sekolah swasta yang memiliki dua jurusan, sepeda motor otomotif dan teknik komputer serta teknik jaringan, tetapi sekolah ini tidak memiliki situs web sehingga banyak orang yang belum tahu mengingat sekolah ini masih baru. Dalam pembuatan situs web ini penulis juga menerapkan metode MVC sebagai opsi dalam pengembangan sistem [5].

\subsection{Framework Codeigniter}

Codeigniter adalah sebuah web aplication framework yang bersifat open source digunakan untuk membangun aplikasi php dinamis. Tujuan utama codeigniter adalah membantu developer untuk mengerjakan aplikasi lebih cepat dari pada menulis semua code dari awal.Codeigniter menggunakan metode Model-View-Controller development pattern.

Codeigniter adalah sebuah framework PHP yangdapat membantu mempercepat developer dalam pengembangan 
aplikasi webberbasis PHP dibanding jika menulis semua kode program dari awal [7].

\subsection{Konsep Model View Controller (MVC)}

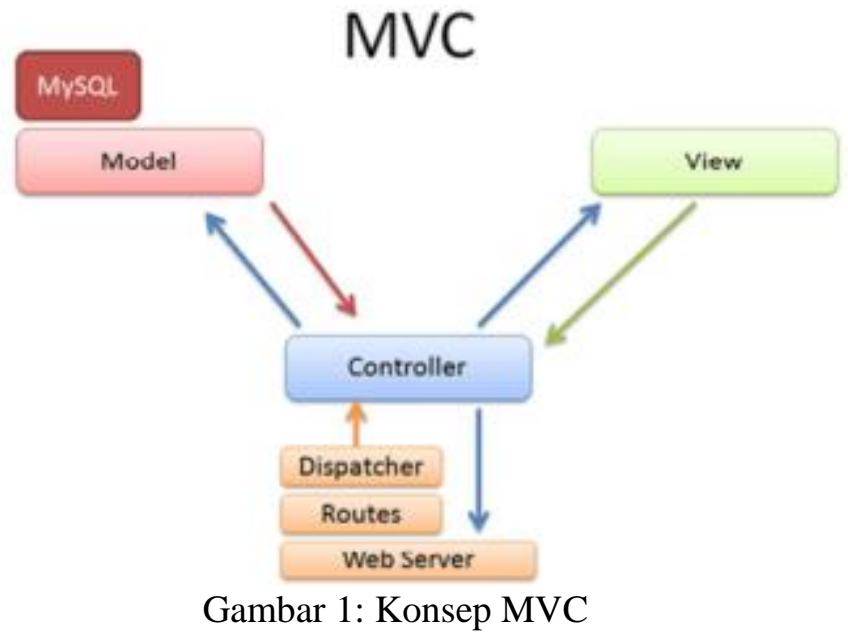

MVC adalah konsep dasar yang harus diketahui sebelum mengenal Codeigniter. MVC sebenarnya adalah sebuah teknik pemrograman yang memisahkan bisnis logic (alur pikir), data logic (penyimpanan data), dan presentasi logic (antarmuka aplikasi).Pola MVC memecah aplikasi menjadi tiga modul: Model View Controller. Gambar 1menggambarkan arsitektur kerangka kerja PHP untuk manajemen basis data berdasarkan MVC [8].

\subsection{Pengujian Sistem}

Blackbox testing adalah tahap yang digunakan untuk menguji kelancaranprogram yang telah dibuat. Pengujian ini penting dilakukan agar tidak terjadikesalahan alur program yang telah dibuat. Blackbox testing yaitu menguji perangkat lunak dari segi spesifikasi fungsional tanpa menguji desain dan kodeprogram[9].

Black Box Testing befokuspada spesifikasi fungsional dari perangkat lunak, kumpulan kondisi input dan melakukan pengetesan pada fungsional program[10].

\subsection{Kerangka Pemikiran}

Kerangka pemikiran memberikan gambaran alur suatu tahapan penelitian akan dilakukan beserta metode yang akan diterapkan di dalamnya.

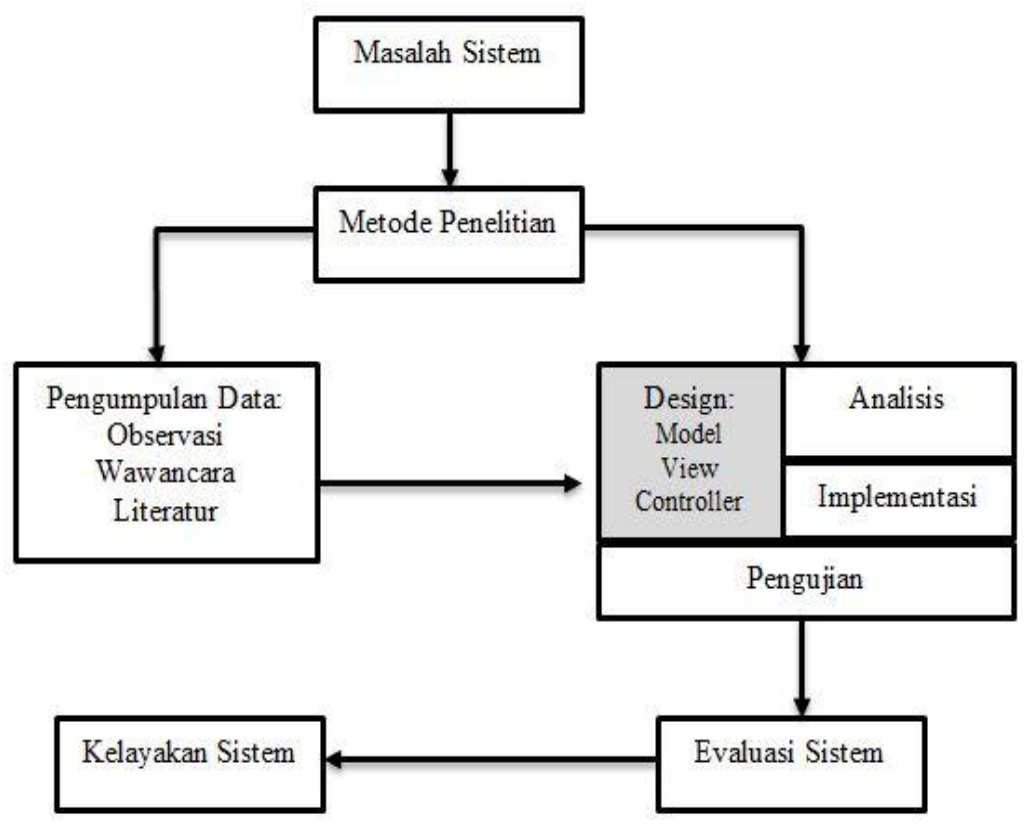

Gambar 2: Kerangka Pemikiran 


\section{METODE PENELITIAN}

Dalam penelitian ini penulis melakukan beberapa metode penulisan untuk mengumpulkan data. Sedangkan metode yang digunakan dalam menunjang penyusunan penelitian ini adalah sebagai berikut :

\subsection{Teknik Pengumpulan Data}

Tahap pertama dilakukan pengumpulan data terkait dengan permasalahan di sekitar sistem dengan menggunakan teknik wawancara, observasi, kuisioner. Dan untuk melengkapi solusi pemecahan permasalahannya dibutuhkan teori-teori yang menjelaskan sistem informasi, framework codeigniter, HTML, PHP, web serta konsep Model view controller (MVC) dengan menggunakan Literatur buku dan studi pustaka

\subsection{Metode Pembangunan Sistem Informasi}

System Development Life Cycle (SDLC) adalah siklus yang digunakan dalam pengembagan perangkat lunak yang didalamnya ada 5 tahap Analisis, perancangan (design), implementasi, pengujian, evaluasi[9].

\section{Analisis}

Analisis merupakanmenganalisa kebutuhan sistem yang akan disusun berdasarkan permasalahanpermasalahan yang muncul pada sistem penjualan.

\section{Desain}

Konsep desain yang digunakan menggunakan Model-View-Controller (MVC) dimana konsep ini membagi tiga tahap dalam mendesain suatu sistem informasi. Tahap ini mengunakan pengambaran berupa diagram LRS, diagram usecase, dan diagram class sebagai mentranslasi kebutuhan perangkat lunak dari tahap analisis kebutuhan ke representasi desain agar dapat diimplmentasikan menjadi program pada tahap selanjutnya.

\section{Implementasi}

Setelah melakukan desain suatu sistem maka tahap selanjutnya bagaimana desain tersebut diimplementasikan ke dalam sebuah framework codeigniter.

\section{Pengujian}

Tahapan pengujian ini menggunakan Black Box Testing. Hal ini dilakukan untuk meminimalisir kesalahan (error) dan memastikan keluaran yang dihasilkan sesuai dengan yang diinginkan.

\section{Evaluasi}

Setelah aplikasi selesai dilakukan maka perlu dilakukan evaluasi, dimana evaluasi ini dapat mendapatkan penilaian dari responden yang sudah melakukan aktivitas di dalam sistem. Data yang sudah terkumpul dari sumber data kemudian dikalkulasikan persentasenya dengan rumus penilaian kelayakan [11].

Dengan : $R S=\frac{n}{N} \times 100 \%$

RS $=$ Persentase sub variabel

$\mathrm{n}=$ Jumlah nilai tiap sub variabel

$\mathrm{N}=$ Jumlah skor maksimum

Tabel 1.Range Persentase Kuisioner Kriteria Kualitatif

\begin{tabular}{ll}
\hline Interval & Kriteria \\
\hline $84,0 \%-100 \%$ & Sangat Baik \\
\hline $68,0 \%-83,9 \%$ & Baik \\
\hline $52,0 \%-67,9 \%$ & Cukup Baik \\
\hline $36,0 \%-51,9 \%$ & Kurang Baik \\
\hline $20,0 \%-35,9 \%$ & Tidak Baik \\
\hline
\end{tabular}

Dalam penelitian ini, aplikasi penjualan perlengkapan dan mainan anak yang dikembangkan dikatakan layak apabila hasil perhitungan (1) skor validasi yang diperoleh $>67 \%$.

\section{HASIL DAN PEMBAHASAN}

\subsection{Analisis}

Pada pembangunan perangkat lunak atau sistem informasi yang pertama kali dilakukan adalah mengalisis kebutuhan sistem yang akan dibuat. Analisis kebutuhan ini kita dapatkan dari permasalahan sistem penjualan yang akan diberikan alternatif solusi. Adapun kebutuhan sistemnya sebagai berikut :

1. Kebutuhan User Non Member:

Non member melihat profile PT Harmoni Lintas Gaya

Non member melihat kategori produk

Non member melihat cara tata cara pembelian barang 
Non member dapat melihat harga dan detail barang Non member dapat melakukan registrasi atau login

2. Kebutuhan User Member atau Pembeli:

Member dapat melakukan edit data user.

Member dapat melihat dan menambahkan produk ke keranjang belanja

Member dapat menghapus dan mengubah jumlah pembelian barang.

Member dapat melakukan transaksi pembelian.

Member dapat men-download bukti pembelian (invoice) pada riwayat transaksi.

Member dapat melakukan konfirmasi pembayaran

3. Kebutuhan Sistem:

Member harus melakukan login terlebih dahulu untuk dapat mengakses aplikasi ini dengan memiliki username dan password agar privasi masing-masing pengguna tetap terjaga keamananya.

Member harus melakukan logout setelah selesai menggunakan aplikasi web.

Sistem mampu mengelola data laporan.

\subsection{Perancangan}

1. Tahap Model

Bagain awal dari perancangan aplikasi adalah menyusun basis data dan membuat model data dalam perancangannya di framework Codeigniter, adapun bentuk basis data bisa dilihat pada gambar berikut:

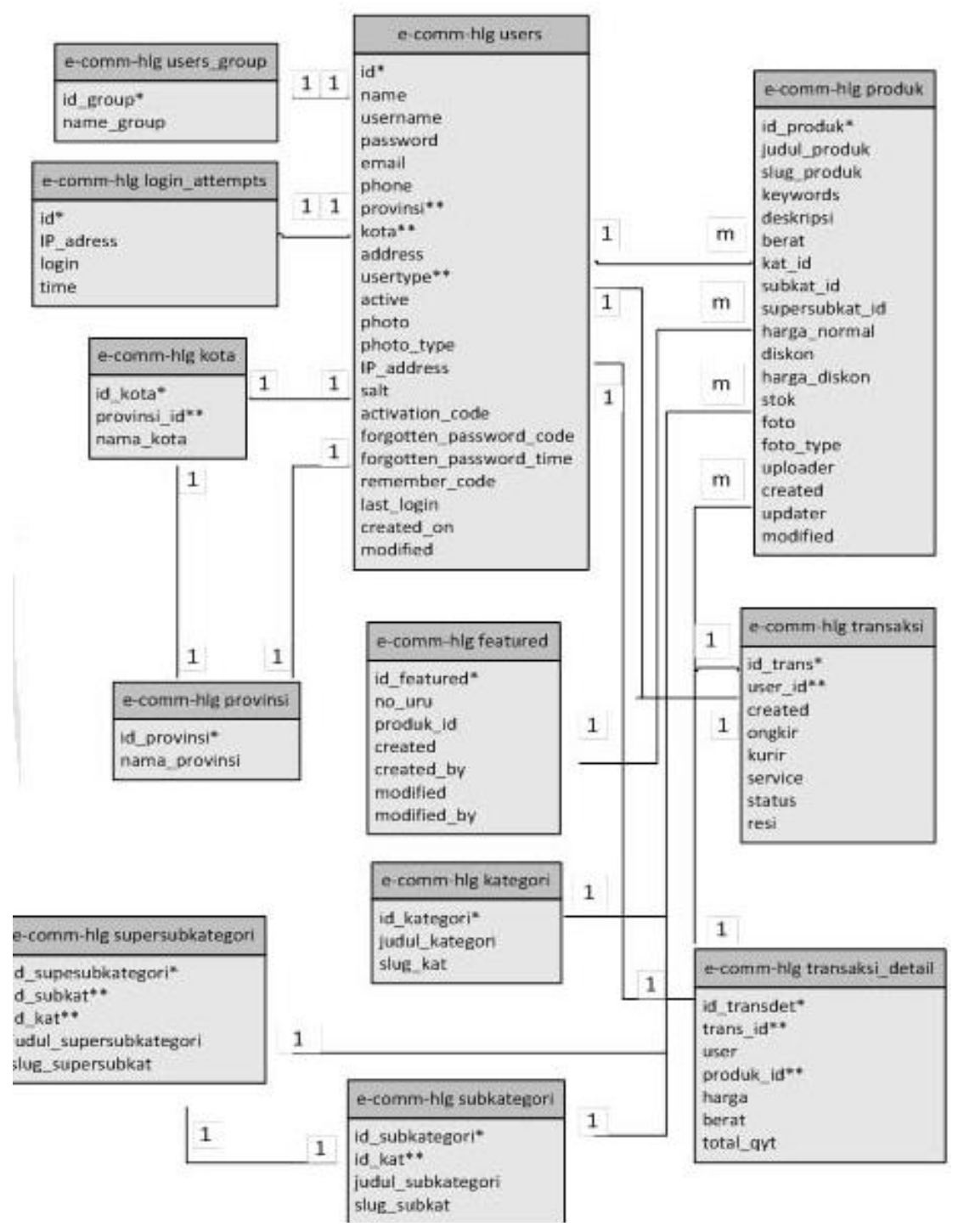

Gambar 3: Model Basisdata dalam bentuk LRS 
2. Tahap View

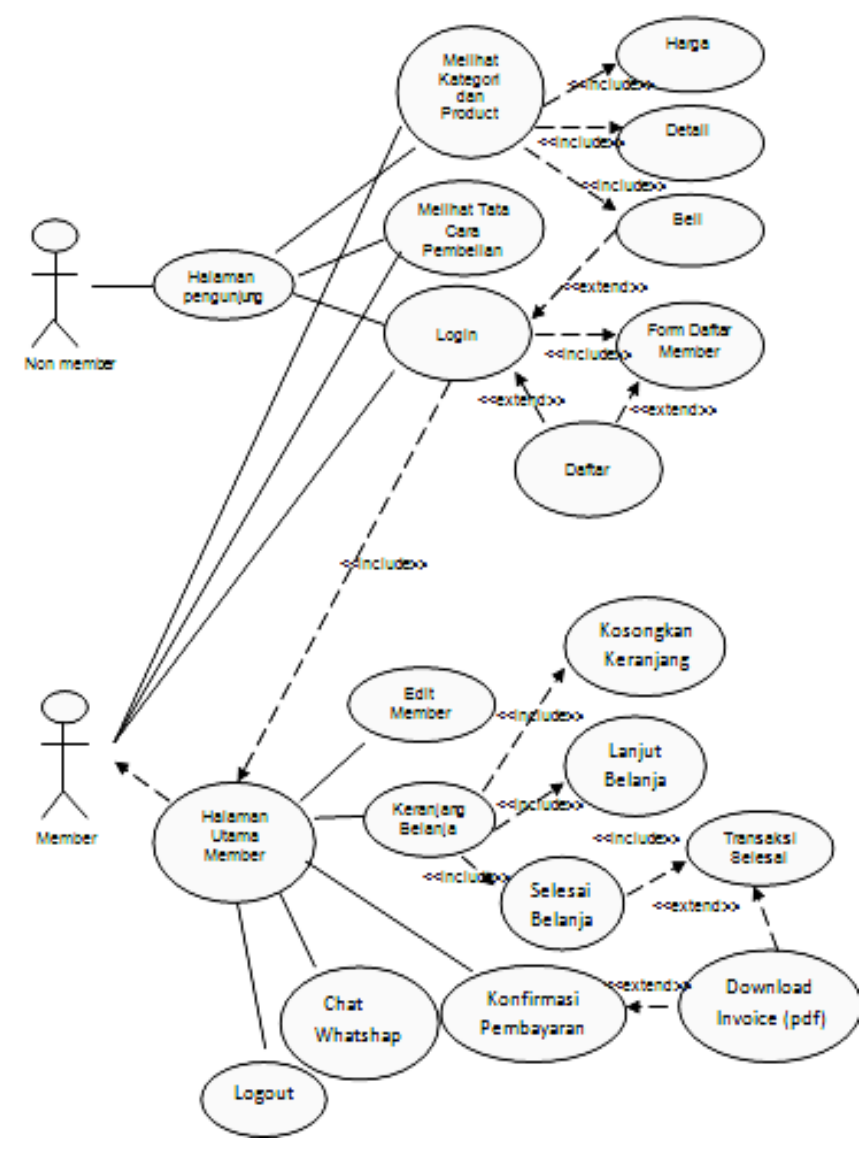

Gambar 4: View dalam Bentuk UseCase Diagram

View atau tampilan halaman end-user pada rancangan sistem penjualan berbasis web ini, dimana User atau konsumen dengan pihak toko tidak bertatap muka secara langsung. Konsumen melakukan pembelian melalui media online. Kebutuhan tampilan (view) diatas dapat digambarkan dengan bentuk diagram usecase. Sistem dapat dibuka oleh non-member sebagai halaman pengunjung, member sebagai halaman anggota atau halaman utama member.

Dari gambar diatas, maka dapat dijelaskan beberapa kebutuhan variabel-variabel yang harus dipenuhi agar sistem dapat berjalan dengan baik, sebagai berikut :

a. Variabel Registrasi

Requirements:

Non member dapat melakukan Registrasi dan Login

Pre-Conditions:

Non Member masuk ke halaman utama

Post-conditions:

Jika Non Member salah input data maka tidak dapat melakukan registrasi dan jika Member salah input username dan password maka tidak dapat login

Failed end Conditions :

Tidak dapat registrasi dan login

Main Flow / Basic Path:

1. Non member membuka website penjualan

2. Non Member mengisi form registrasi

3. Non Member menjadi member

4. Member mengetik username dan password pada form login

b. Variabel Melihat Kategori dan Produk

Requirements:

Member dapat melihat kategori dan produk

Pre-Conditions: 
Member masuk ke halaman utama

Post-conditions:

Jika member berhasil melakukan login maka member dapat melihat kategori dan produk

Failed end Conditions :

Tidak dapat melihat dan memilih kategori dan produk

Main Flow / Basic Path:

1. Member melakukan login

2. System menampilkan halaman utama

3. Member dapat melihat dan memilih kategori dan produk

c. Variabel Keranjang Belanja

Requirements:

Member dapat mengelola keranjang belanja

Pre-Conditions:

Member masuk ke halaman keranjang belanja

Post-conditions:

Jika member selesai memilih produk maka masuk kekeranjang belanja

Failed end Conditions :

Jika member belum memilih produk maka tidak dapat mengelola keranjang belanja

Main Flow / Basic Path:

1. Member memilih produk

2. System menampilkan halaman keranjang belanja

3. Member dapat mengelola keranjang belanja (kosongkan keranjang, lanjut belanja dan selesai belanja)

4. Member memilih selesai belanja

5. Sistem menampilkan download (invoice) detail pembelian dan tatacara pembayaran

d. Variabel Konfirmasi Pembayaran

\section{Requirements:}

Member dapat mengisi konfirmasi pembayaran

Pre-Conditions:

Member masuk ke halaman konfirmasi pembayaran

Post-conditions:

Jika member selesai melakukan transfer pembayaran

Failed end Conditions

Jika member belum melakukan pembayaran sesuai dengan jumlah total invoice, maka member tidak dapat mnegisi konfirmasi pembayaran

Main Flow / Basic Path:

1. Member memilih produk

2. System menampilkan halaman keranjang belanja

3. Member dapat mengelola keranjang belanja (kosongkan keranjang, lanjut belanja dan selesai belanja)

4. Member memilih selesai belanja

5. System menampilkan download (invoice) detail pembelian dan tatacara pembayaran

6. Member mengisi konfirmasi pembayaran setelah melakukan transfer pembayaran atau dapat mengkonfirmasi pembayaran melalui whatsapp

\section{Tahap Controller}

Pada tahap ini dibentuknya class-class dari kebutuhan sistem yang saling memiliki relasi dari class-class yang dibentuk, Pada gambar class memberikan ilustrasi relasi antar class yang berisikan basisdata dan instruksi class yang berada di dalam class. Class kategori berelasi dengan class subkategori dan supersubkategori. Class produk memiliki relasi dengan class kategori dan class transaksi. Class transaksi memiliki relasi dengan class transaksi detail. Class admin memiliki relasi class transaksi, produk dan class users. Class member memiliki relasi dengan class users dan class transaksi.adapun bentuk class dari controller dapat dilihat pada gambar berikut ini: 


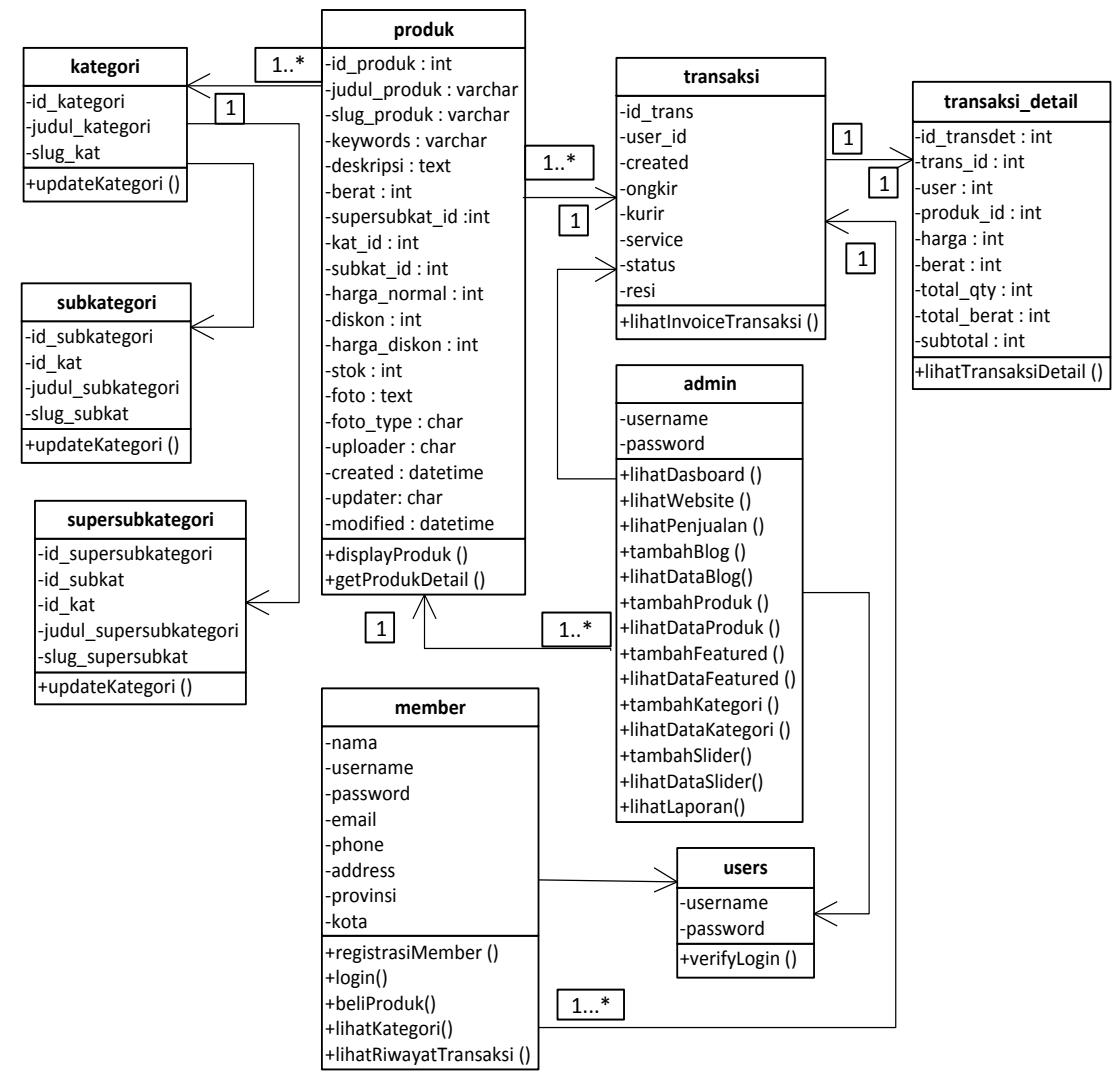

Gambar 5: Controller dalam Bentuk Class Diagram

\subsection{Implementasi}

Setelah konsep Model View Controller diterapkan pada rancangan sistem informasi penjualan dengan menggunakan framework Codeigniter, maka hasil dari tampilan (interface) rancangan tersebut dapat dilihat dibawah ini.

\section{a. Halaman Login}

Tampilan (interface) halaman login merupakan langkah awal user dalam memulai transaksi pembelian dengan cara memasukan username dan password yang sudah terdaftar di dalam sistem penjualan secara online. Jadi user dapat melakukan login setelah melakukan registrasi ke dalam sistem. Apabila user tidak melakukan login maka order pembelian barang tidak bisa dilakukan.

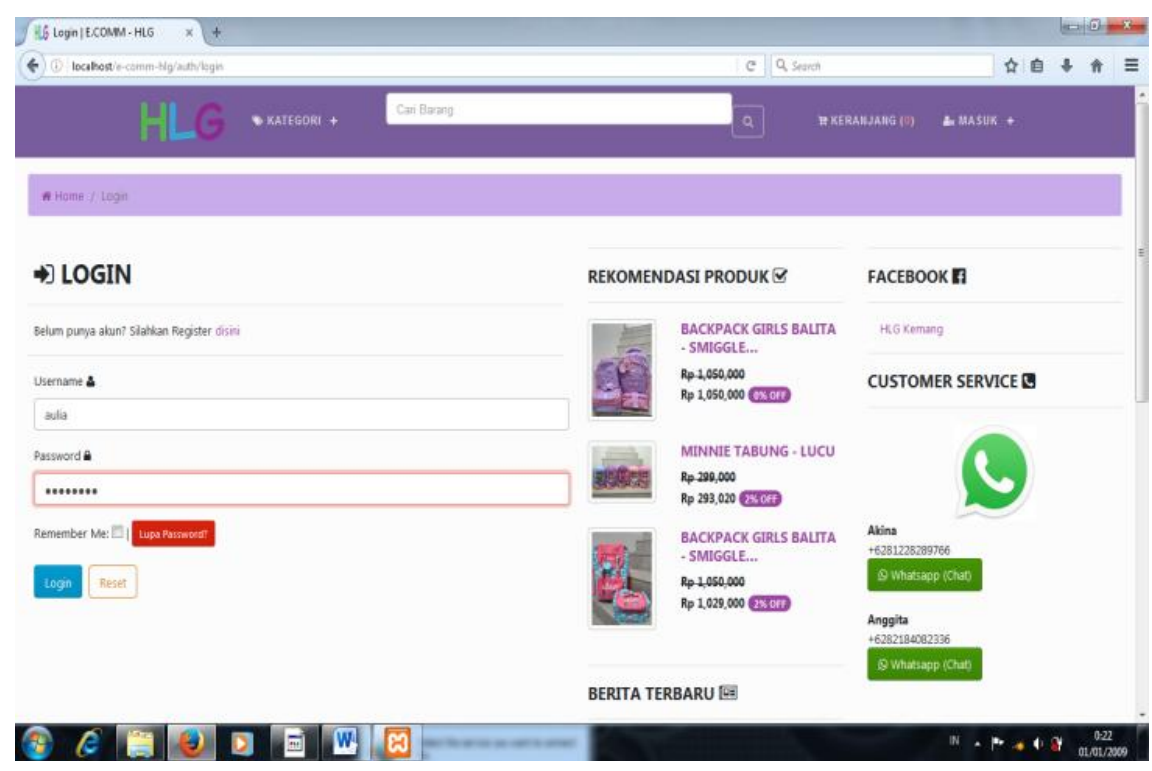

Gambar 6: InterfaceLogin 


\section{b. Halaman Menu Kategori}

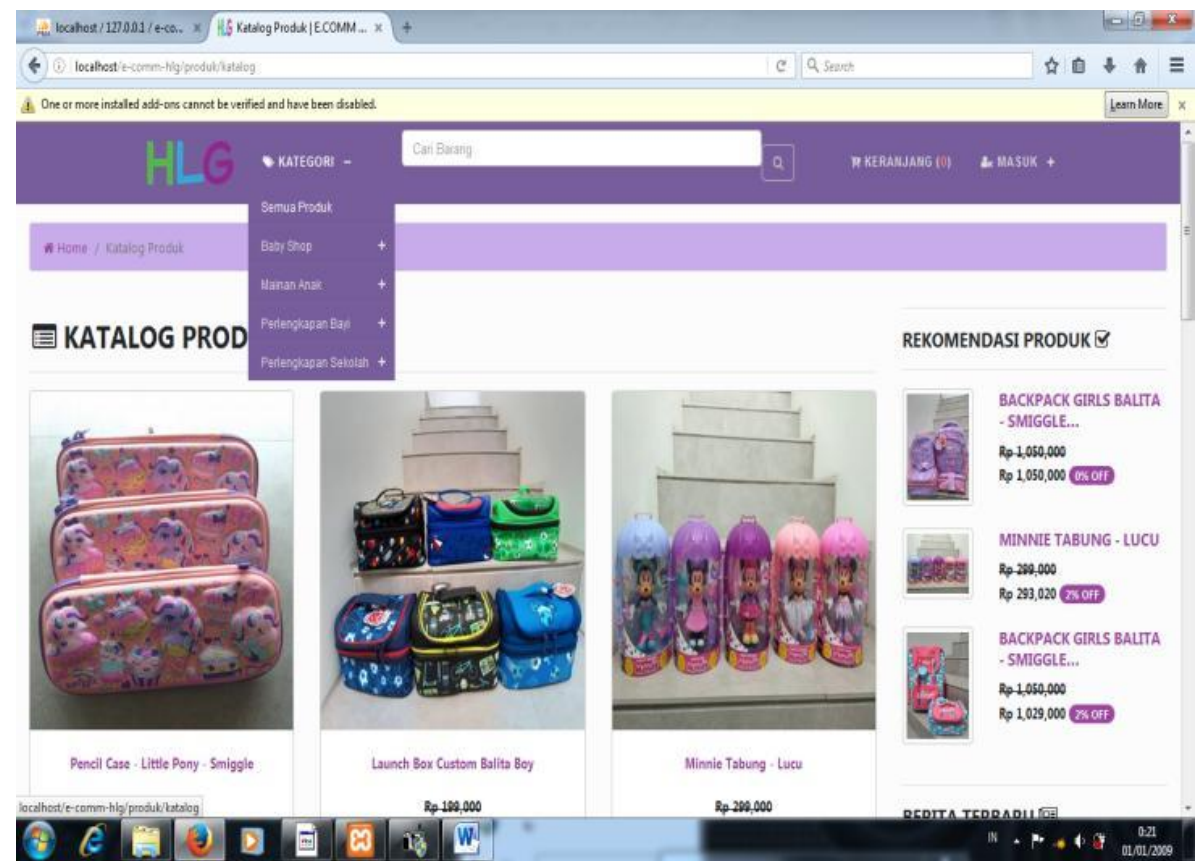

Gambar 7: Tampilan Menu Kategori

Tampilan (interface) menu kategori adalah halaman yang memberikan pilihan beberapa kategori kelompok dari produk yang akan dijual sehingga user dapat dengan mudah mencari produk atau barang yang sesuai dengan keinginan. User atau pembeli dapat melakukan pencarian barang yang diinginkan dengan memilih kategori yang diinginkkan sehingga akan memudahkan proses pencarian barang.

\section{c. Tampilan Keranjang Belanja}

Tampilan (interface) keranjang belanja merupakan tampilan halaman yang berisikan produk-produk yang sudah dipilih dan masuk dalam order pembelian yang nantinya masuk dalam nota transaksi pembelian barang. Proses ini dapat dilihat setelah user atau pembeli telah melakukan login dan telah melakukan pemilihan barang yang diinginkan. Jadi keranjang belanja merupakan kumpulan barang yang telah dipilih.

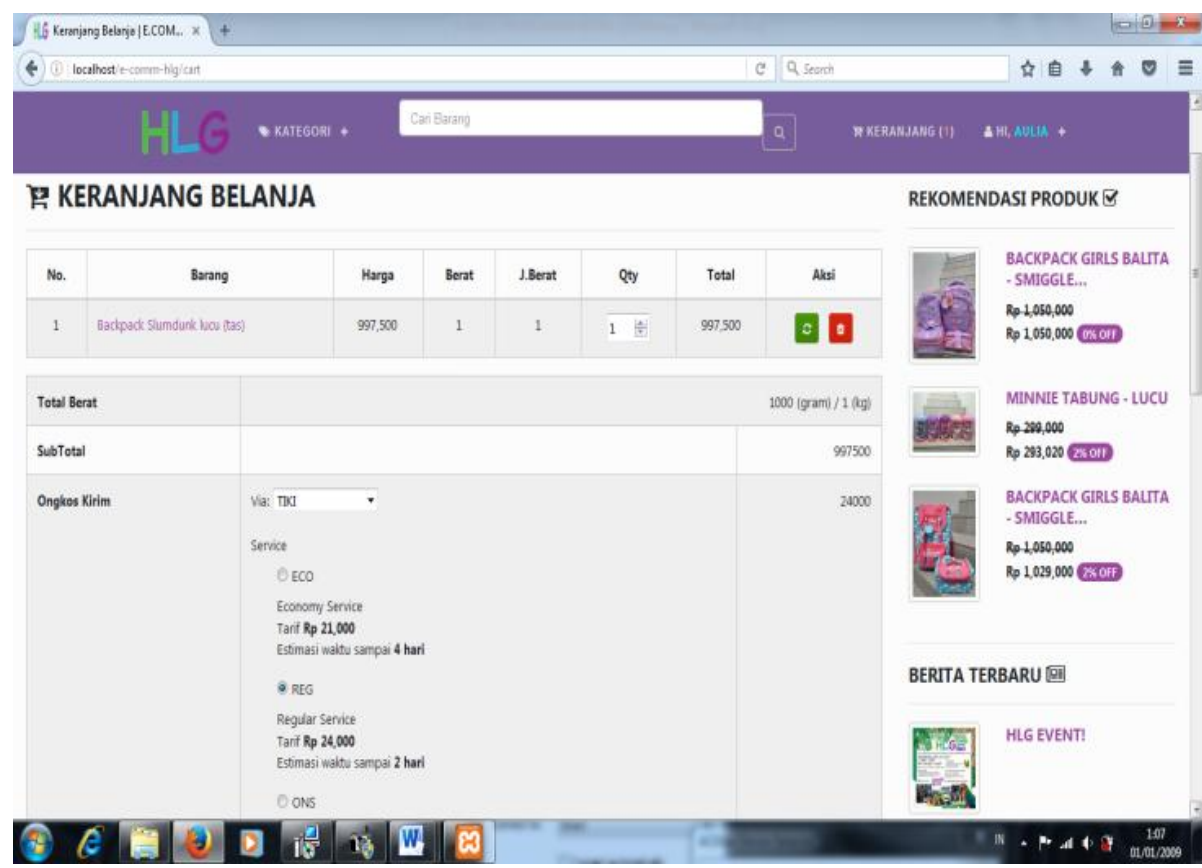

Gambar 8: Tampilan Keranjang Belanja 


\section{d. Halaman Transaksi (Invoice)}

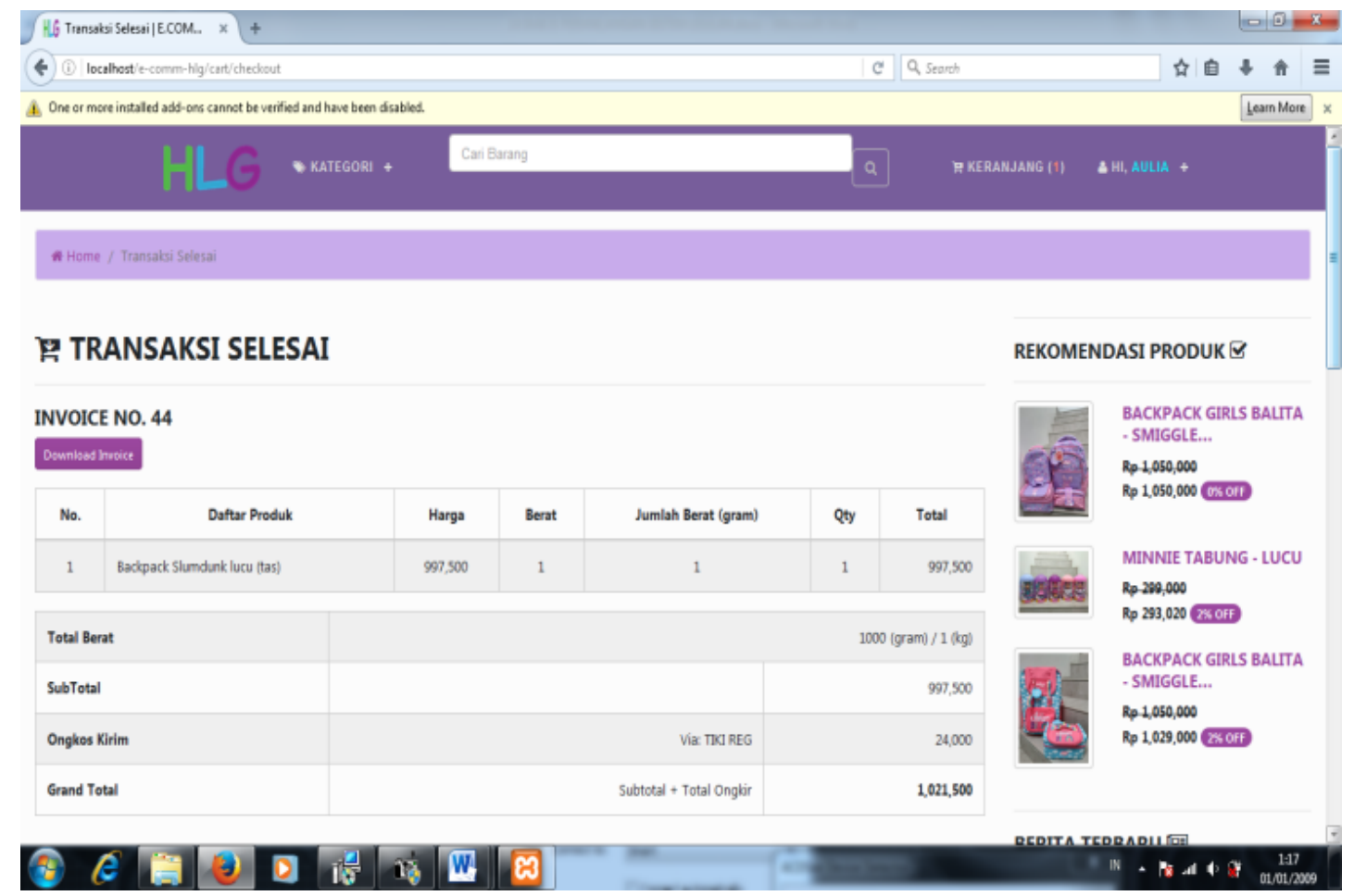

Gambar 9: TampilanTransaksi (Invoice)

Tampilan (interface) halaman transaksi berisikan data-data transaksi yang masuk dalam keranjang belanja yang telah disetujui oleh member (user). Detail dari tampilan transaksi disertai dengan nama barang, qty, harga, ongkir dan total sehingga pembeli dapat membayarkan sejumlah uang yag tertera dalam tampilan tersebut.

\section{e. Riwayat Transaksi}

Riwayat transaksi adalah histori transaksi yang pernah dilakukan oleh user, sehingga apabila user ingin melihat apa transaksi apa saja yang telah dilakukan di dalam sistem.

\subsection{Pengujian}

Pada tahapan ini pengujian yang digunakan yaitu Blackbox Testing, penulis melakukan uji coba terhadap sistem yang telah dibangun dengan hasil sebagai berikut :

a. Pengujian Terhadap Form Login Member

Tabel 2:Hasil Pengujian Black Box Testing Halaman Login Member

\begin{tabular}{|c|c|c|c|c|}
\hline No. & pengujian & Test case & Hasil yang diharapkan & $\begin{array}{c}\text { Hasil } \\
\text { pengujian }\end{array}$ \\
\hline 1. & $\begin{array}{l}\text { Username dan pass- } \\
\text { word tidak diisi kemu- } \\
\text { dian klik tombol login }\end{array}$ & $\begin{array}{l}\text { Username: } \\
\text { song) } \\
\text { Password: } \\
\text { song) }\end{array}$ & $\begin{array}{l}\text { Sistem akan menolak akses user } \\
\text { menampilkan "Username tidak } \\
\text { ditemukan dan password mo- } \\
\text { hon di isi" }\end{array}$ & $\begin{array}{l}\text { Sesuai } \\
\text { harapan / } \\
\text { Valid }\end{array}$ \\
\hline 2. & $\begin{array}{l}\text { Isi user } \\
\text { word } t \\
\text { kosong }\end{array}$ & $\begin{array}{l}\text { Username: aulia } \\
\text { Password: } \quad \text { (ko- } \\
\text { song) }\end{array}$ & $\begin{array}{l}\text { Sistem akan menolak akses user } \\
\text { dan menampilkan "Password } \\
\text { mohon di isi" }\end{array}$ & $\begin{array}{r}\text { Se } \\
\text { hara } \\
\mathrm{V}\end{array}$ \\
\hline 3. & $\begin{array}{l}\text { Usern } \\
\text { (koso } \\
\text { diisi } 1\end{array}$ & $\begin{array}{l}\text { Username: } \\
\text { song) } \\
\text { Password: } \\
\text { lia123 }\end{array}$ & $\begin{array}{l}\text { lenolak akse: } \\
\text { ilkan "User } \\
\text { an" }\end{array}$ & $\begin{array}{r}\text { Sest } \\
\text { harap } \\
\text { Val }\end{array}$ \\
\hline 4. & $\begin{array}{l}\text { Isi salah } \\
\text { salah pa } \\
\text { atau pa }\end{array}$ & $\begin{array}{l}\text { Username: aulia } \\
\text { (benar) } \\
\text { Password: au- } \\
\text { lia12 (salah) }\end{array}$ & $\begin{array}{l}\text { Sistem akan menolak akses user } \\
\text { dan menampilkan "Gagal lo- } \\
\text { gin". }\end{array}$ & $\begin{array}{l}\text { Sesuai } \\
\text { harapan/ } \\
\text { Valid }\end{array}$ \\
\hline & Isi username dan & Username: auli & en & Sesua \\
\hline
\end{tabular}




\begin{tabular}{lllc}
\hline password dengan data & (benar) & dan kemudian langsung me- & harapan/ \\
yang benar kemudian & Password: au- & $\begin{array}{l}\text { nampilkan menu utama "Login } \\
\text { berhasil. Selamat berbelanja". }\end{array}$ & Valid \\
klik tombol login & lia123 (benar) & \\
\hline
\end{tabular}

b. Pengujian Terhadap Form Halaman Utama Member

Tabel 3:Hasil Pengujian Black Box Testing Halaman Utama Member

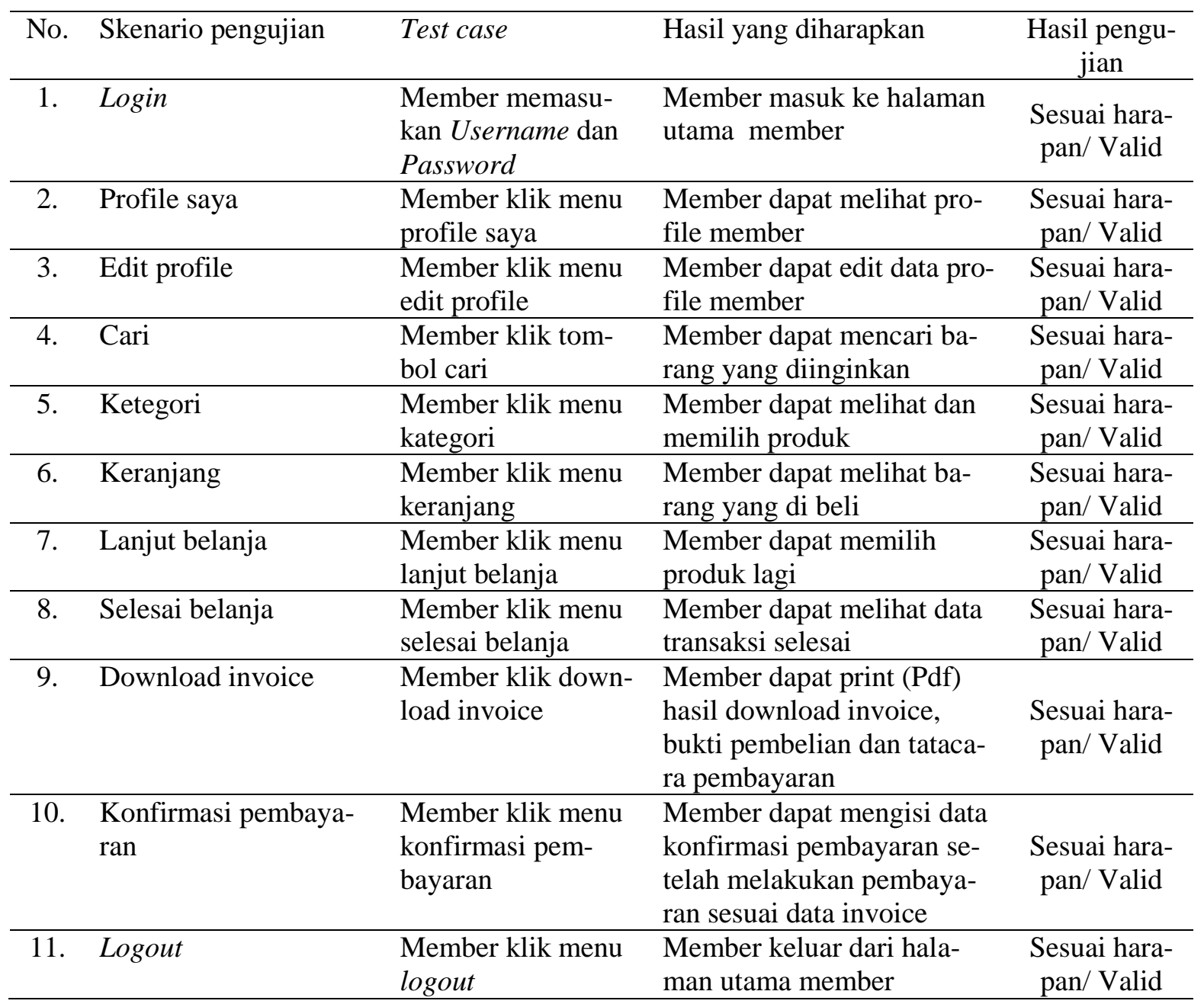

\subsection{Evaluasi}

Pada tahap ini peneliti menganalisi data dari hasil pengisian kuisioner yang diisi oleh responden untuk menghasilkan validitas aplikasi yang baik. Validitas yang digunakan adalah validitas logis, yang mana kuisioner disusun berdasarkan kisi-kisi dan usaha yang sangat hati-hati sehingga secara logika instrumen itu dicapai menurut validitas yang diinginkan. Berdasarkan kuisioner responden, didapatkan persentase setiap indikator kuisioner. Persentase indikator aplikasi penjualan online dapat dilihat dalam tabel berikut:

Tabel 4. Persentase Persepsi Responden Terhadap Penjualan Online

\begin{tabular}{clcc}
\hline No. & Aspek (Kriteria) & $(\%)$ & Kategori \\
\hline 1 & Materi & $84.4 \%$ & Sangat Baik \\
\hline 2 & Tampilan Web & $80.2 \%$ & Baik \\
\hline 3 & Kualitas Web & $83.7 \%$ & Baik \\
\hline & Rata-rata & $82.6 \%$ & Baik
\end{tabular}

Sumber : Anwar (2020)

Dari uji coba yang dilakukan kepada responden dengan nilai skor validasi 82,6\% secara keseluruhan dapat disimpulkan bahwa aplikasi penjualan perlengkapan dan mainan anak yang telah dikembangkan sudah layak digunakan sebagai penunjang pemasaran dan penjualan dalam meningkat market perusahaan. 


\section{KESIMPULAN}

Rancangan sistem informasi atau aplikasi penjualan perlengkapan dan mainan anak berbasis web ini dapat memberikan keuntungan dari dua pihak yaitu pihak perusahaan dan pihak user (pembeli). Bagi pihak perusahaan dengan adanya sistem informasi ini dapat memberikan kemudahan dalam pemasaran dan penjualan produk yang dijual. Sedangkan bagi user (pembeli) aplikasi ini memberikan kemudahan akses dalam mencari produk yang diinginkan.Dengan menggunakan framework Codeigniter perancangan aplikasi penjualan ini dapat disusun dengan lebih mudah dan lebih terarah pembagian struktur pemrogramanannya. Konsep Model View Controller (MVC) memberikan penyusunan coding program lebih mudah dibuat konsepnya dan mempermudah pemeriksaan bagianbagian dari coding yang dibuat. Desain tampilan aplikasi (View) dapat dibuat lebih dinamis dan menarik dengan konsep MVC ini. Dengan menggunakan pengujian black box, bagian-bagian input data dilakukan validasi data agar dapat dihindari dari kesalahan (error).

Dari pembahasan diatas mengenai penjualan berbasis website, penulis menarik kesimpulan dari keseluruhan pokok pembahasan, pembuatan aplikasi website ini diharapkan dapat membantu mengembangkan pemasaran yang ada di PT Harmoni Lintas Gaya, yaitu dalam penyebaran informasi barang dan pembelian barang yang saat ini akan dapat dilakukan secara online. Penggunaan sistem informasi penjualan ini dapat menyimpan dan menampilkan data penjualan yang dimasukan oleh pengguna secara online. data kategori, daftar member, dan laporan penjualan. Sistem informasi penjualan perlengkapan dan mainan anak berbasis web ini dapat diterapkan karena nilainya adalah $82.6 \%$ dari nilai kelayakan.

\section{DAFTAR PUSTAKA}

[1] R. Harminingtyas, "Analisis Layanan Website Sebagai Media Promosi, Media Transaksi Dan Media Informasi Dan Pengaruhnya Terhadap Brand Image Perusahaan Pada Hotel Ciputra Di Kota Semarang," J. STIE Semarang, vol. 6, no. 3, pp. 37-57, 2014.

[2] Nazarullah, "Efektivitas Cybermedia Sebagai Sarana Komunikasi Dakwah Modern," J. Peurawi, vol. 1, no. 1, pp. 1-10, 2017.

[3] S. Pastima and A. Kasnady, “Analisis Model View Controller (Mvc) Pada Bahasa Php,” J. ISD, vol. 2, no. 2, pp. 56-66, 2016.

[4] Diana and Febrianti, "Implentasi Model View Controller (MVC) Pada Aplikasi Doa Harian Untuk Anak Muslim Berbasis Android," J. Inform., vol. 17, no. 1, pp. 11-21, 2017, doi: 10.1007/978-1-4842-2538-7_10.

[5] K. Wijaya and A. Christian, "Implementasi Metode Model View Controller ( MVC ) Dalam Rancang Bangun Website SMK Yayasan Bakti Prabumulih,” Paradig. - J. Komput. dan Inform., vol. XXI, no. 1, pp. 1-8, 2019, doi: 10.31294/p.v20i2.

[6] Suendri, "Penerapan Konsep Model View Controller Pada Perancangan Sistem Manajemen," vol. 3, no. 2, pp. 36-45, 2018.

[7] L. Hakim, Membangun Web Berbasis PHP dengan Framework Codeigniter. Yogyakarta: Lokomedia, 2010.

[8] C. Supaartagorn, "PHP Framework for Database Management Based on MVC Pattern," Int. J. Comput. Sci. Inf. Technol., vol. 3, no. 2, pp. 251-258, 2011, doi: 10.5121/ijcsit.2011.3219.

[9] R. AS and M. Shalahuddin, Rekayasa Perangkat Lunak Terstruktur Dan Berorientasi Objek. Bandung: INFORMATIKA, 2015.

[10] M. S. Mustaqbal, R. F. Firdaus, and H. Rahmadi, "Pengujian Aplikasi menggunakan Black Box Testing Boundary Value Analysis (Studi Kasus: Aplikasi Prediksi Kelulusan SNMPTN)," J. Ilm. Teknol. Inf. Terap., vol. I, no. 3, pp. 31-36, 2015.

[11] Arikunto and Suharsimi, Dasar-Dasar Evaluasi Pendidikan. Jakarta: Bumi Aksara, 2013. 